\title{
The adenosinergic immuno-modulatory drugs
}

\author{
Akio Ohta and Michail Sitkovsky \\ New England Inflammation and Tissue protection Institute, Northeastern University, 113 Mugar \\ Health Science Building, 360 Huntington Avenue, Boston, MA 02115, United States
}

\begin{abstract}
Hypoxia-driven increase of extracellular adenosine in local tissue microenvironments of inflamed and cancerous tissues plays a critical role in the regulation of tissue destruction by activated immune cells. Accumulated data suggest that injection or consumption of A2A adenosine receptor (A2AR) antagonists may represent a drug treatment that diminishes adenosine-mediated immunosuppression. Since this, in turn, enhances the immune response, inhibition of adenosine-A2AR signaling may be a promising approach to enhance anti-tumor or anti-pathogen immune response. Patients with disorders characterized by excessive inflammation may be at risk to A2AR antagonists (e.g. caffeine) because of the effect to increase inflammatory damage secondary to enhanced immunity. On the other hand, enhancement of hypoxia-adenosinergic immunomodulatory pathways may be beneficial to prevent inflammatory tissue destruction.
\end{abstract}

\section{Introduction}

Immune cells have evolved to destroy pathogens by direct cell cytotoxicity and by secretion of pathogen-destroying or pathogen-neutralizing molecules. Inflammatory mediators such as cytokines and reactive oxygen/nitrogen species can non-specifically cause damage to local tissues that may compromise normal tissue function. Therefore, inflammatory response must be carefully regulated to effectively clear pathogens but also to prevent critical inflammatory damage to vital organs [1,2]. On one hand, anti-inflammatory drugs are desirable to stop uncontrolled inflammatory tissue injury. On the other hand, there is also a need in drugs to enhance anti-pathogen or anti-tumor immune responses in vivo. Thus, it is important to extensively investigate a key physiological mechanism that regulates inflammatory response in vivo.

\section{Adenosinergic protection of normal tissues}

The recognition of cAMP as an immunosuppressive second messenger molecule initiated investigations leading to current understandings on the implication of A2AR in tissue protection. It has been demonstrated that cAMP is capable of inhibiting effector functions of $\mathrm{T}$ cells. Activation of cAMP-dependent protein kinase (PKA) was shown to inhibit $\mathrm{T}$ cell receptor-triggered trans-membrane signaling pathways $[3,4]$. Subsequent studies identified several intracellular signaling molecules that receive phosphorylation by PKA. For example, it was shown that PKA-mediated phosphorylation of $\mathrm{COOH}$-terminal Src kinase (Csk) induced

\footnotetext{
(C) 2009 Elsevier Ltd. All rights reserved

Corresponding author: Akio Ohta (Phone: 617-373-5188, Fax: 617-373-5834).

E-mail: a.ohta@neu.edu (AO), m.sitkovsky@neu.edu (MS)
}

Publisher's Disclaimer: This is a PDF file of an unedited manuscript that has been accepted for publication. As a service to our customers we are providing this early version of the manuscript. The manuscript will undergo copyediting, typesetting, and review of the resulting proof before it is published in its final citable form. Please note that during the production process errors may be discovered which could affect the content, and all legal disclaimers that apply to the journal pertain. 
phosphorylation of Lck kinase [5]. This event resulted in negative regulation of Lck, and represents one of the important reasons for cAMP-mediated inhibition of $\mathrm{T}$ cell activation.

Pharmacological induction of cAMP is clearly suppressive to T cell activation. However, cAMP's physiological immunoregulatory role in inflammation was uncertain. Further studies were required to determine if cAMP is upregulated in the course of inflammation and plays a role in physiological down-regulation of inflammation. Indeed, it is well established that cAMP is induced by Gs protein-coupled receptor ligation, and some of them, including histamine, $\beta$ adrenergic, prostaglandin, and adenosine receptors can inhibit $\mathrm{T}$ cell function when pharmacologically activated. It was not known, however, if any of these receptors play a crucial role in physiological down-regulation of inflammation due to spontaneous accumulation of a ligand.

Appropriate control of inflammatory response is vital to preserve normal tissue functions. Excessive collateral damage to healthy tissues threatens tissue functions, and should be stopped by an immunomodulatory mechanism which reacts quickly to tissue damage. One candidate for such a mechanism is extracellular adenosine. Indeed, increase of adenosine levels has been demonstrated in inflammation such as asthma and sepsis. Upon host recognition of a pathogen, inflammatory cells try to destroy the infected area in order to eliminate existing pathogens. This danger response damages not only infected cells but also surrounding components including non-infected cells and blood vessels. The disturbance in blood supply to local tissues decreases oxygen supply downstream of the damaged blood vessels, and local hypoxia ensues. Hypoxia regulates adenosine metabolism toward extracellular accumulation of adenosine. First of all, hypoxia increases enzymatic catabolism of extracellular ATP to adenosine [1,2]. The source of extracellular ATP may be efflux from intracellular pool. The greater release of ATP is expected from damaged/dead cells in inflamed tissue. Hypoxia is known to upregulate apyrase and 5'-nucleotidase, which degrade ATP into adenosine. Phosphorylation of adenosine to AMP by adenosine kinase also decreases under hypoxia. In addition, hypoxia can inhibit cellular adenosine uptake by membrane nucleoside transporter. Taken together, these changes facilitate increase in extracellular adenosine concentration in hypoxic tissue microenvironment $[1,2]$.

\section{Critical role of A2AR in the control of inflammation}

There are four distinct receptor subtypes for adenosine, i.e. A1, A2A, A2B and A3 adenosine receptors [7]. Adenosine receptors are G-protein coupled receptors and particularly Gs-proteincoupled A2A and A2B adenosine receptors can increase intracellular cAMP levels by activating adenylate cyclase. Expression pattern of adenosine receptor subtypes varies dependent on cell types. Pharmacological and biochemical studies established that A2AR are predominant subtype in immune cells $[4,6]$ and adenosine-A2AR interaction is capable of inhibiting inflammation by cAMP induction. The anti-inflammatory effects of extracellular adenosine through adenosine receptor signaling has been known and investigated for a long time [7]. Others have shown that anti-inflammatory drugs, such as methotrexate, sulfasalazine and aspirin, exert their anti-inflammatory effects by triggering the accumulation of extracellular adenosine in tissues [8,9]. The next question was whether the adenosine-A2AR pathway is actually involved in the regulation of activated immune cells in vivo.

A2AR-deficient mice were first developed in order to study cardiovascular and neurological systems where A2ARs are widely distributed [10,11]. A2AR-deficient mice quickly became a valuable research tool in immunological studies of A2AR function. We hypothesized that if the A2AR-mediated signaling is negatively regulating overactive immune cells, the intensity and duration of inflammatory responses will be increased in A2AR-deficient mice. The induction of hepatic inflammation in A2AR-deficient mice provided an evidence for the 
physiological immunoregulatory role of A2AR. To induce T cell-dependent acute hepatitis, we injected concanavalin A into mice at a dose creating moderate liver damage in wild-type mice. The same dose of concanavalin A in A2AR-deficient mice, however, was much more devastating compared to wild-type mice [12]. In the same A2AR-deficient mice, concanavalin A injection resulted in sustained and elevated levels of pro-inflammatory cytokines [12]. Augmented inflammatory response in A2AR-deficient animals was also observed in $\mathrm{CpG}$ oligonulceotide-activated myeloid cells, ischemia-reperfusion injury, sepsis, and toxininduced lung inflammation [13-16]. In addition to cytokines, A2AR stimulation suppresses leukocytes infiltration in response to inflammatory chemokines such as RANTES, MCP-1 and IL-8 [17]. These studies demonstrate a crucial immunosuppressive role of A2AR in pathophysiological conditions.

A2B adenosine receptors (A2BR) are also Gs-coupled receptors which are co-expressed with A2AR in immune cells. Recent development of A2BR-selective agents and A2BR-deficient mice revealed various functions of A2BR in inflammation. Stimulation of A2BR upregulates IL-6 production, and plays a proinflammatory role in the exacerbation of allergic asthma and colitis [18-20]. However, studies using gene-deficient mice showed an anti-inflammatory role of A2BR, i.e. spontaneous vascular inflammation and exacerbated lung injury in A2BRdeficient mice [21-23]. Since A2BR are expressed on both immune cells and epithelial cells, these controversial results may be caused by difference in cell type-specific responses to adenosine via A2BR during inflammation.

\section{The hypoxia-adenosinergic pathway control over-activation of immune cells}

Extracellular adenosine increases not only by the inhibition of adenosine kinase [24] but also due to activities of 5'-ectonucleotidase and apyrase, cell surface enzymes that degrade extracellular ATP to adenosine [25-27]. Hypoxia-inducible factor-1 $\alpha$ (HIF-1 $\alpha)$-mediated induction of 5'-nucleotidase plays an important role in the accumulation of extracellular adenosine in hypoxic tissues [1,25]. These findings extended into studies to determine if hypoxia triggers immunosuppressive pathways. Whole body exposure of mice to hypoxia ( $10 \%$ oxygen) significantly increased adenosine concentration in the blood. Mice exposed to whole body hypoxia were significantly resistant to toxin-induced lung injury and concanavalin Ainduced liver injury revealing that total body hypoxia decreased inflammatory tissue damage $[15,28]$. This inhibition of inflammatory tissue damage was, at least in part, mediated by adenosine-A2AR pathway.

Thus, adenosine-mediated regulation of inflammatory responses can be summarized as follows: Inflammatory tissue damage causes an interruption of the blood supply to the area of inflamed tissue. The ensuing local tissue hypoxia will result in the accumulation of extracellular adenosine which will feedback to activate adenosine receptors on activated immune cells. Activation of A2AR inhibits T cell receptor and toll-like receptor signaling pathways subsequent to the rise in intracellular levels of cAMP. At critical levels of inflammation, the adenosine-A2AR negative feedback mechanism serves as a second signal to down-regulate inflammation.

\section{Exaggeration of inflammation by caffeine consumption}

Current data strongly suggests that drugs that interfere the hypoxia-adenosinergic signaling can weaken the tissue protective mechanism and result in the enhancement of the inflammatory response. Indeed, interruption of adenosine-A2AR pathway can augment inflammation as demonstrated in exacerbation of inflammatory tissue damage by an A2AR antagonist ZM241385 [12]. Interestingly, there are naturally occurring adenosine rececptor antagonists, including caffeine. Caffeine has multiple biochemical targets, e.g. cAMP phosphodiesterase, phosphatidylinositol-3-kinase, and A1 and A2A adenosine receptors [29,30]; however, 
adenosine receptors are the most potent target of caffeine. Caffeine requires more than 20times higher concentration to activate mechanisms other than adenosine receptor antagonism [29]. We found that caffeine could enhance inflammatory tissue damage by A2AR-dependent mechansim [31]. It is of clinical importance that the intensity of acute inflammation may be exaggerated in caffeine-consuming humans because blood caffeine concentration in caffeine consumers is usually high enough to block A2AR. Therefore, anti-hypoxia-adenosinergic drugs should be considered -as the inflammation itself- the "double-edged sword". One might be better to avoid A2AR antagonists if suffering from inflammatory disorders. However, it should be noted that the enhancement of inflammation is favorable in some situations, e.g. treatment of cancer.

\section{Targeting A2AR to improve immunotherapy of cancer}

Cancer immunotherapy by endogenously developed or adoptively transferred anti-tumor $\mathrm{T}$ cells is complementary to conventional treatments by surgery, radiotherapy or chemotherapy $[32,33]$. However, a potential obstacle in cancer immunotherapy is that malignant cells can create a self-protective, immunosuppressive tumor microenvironment preventing tumor destruction by anti-tumor T cells [34]. Indeed, T cell infiltration in tumors has been demonstrated in many human patients. These tumor-infiltrating $\mathrm{T}$ cells are not active in tumor microenvironment despite recognition of the tumor a foreign antigen. Therefore, even when tumor cells express antigens and there is a significant accumulation of tumor antigen-specific $\mathrm{T}$ cells in the tumor, the incidence of complete tumor destruction remains very low $[35,36]$. Interestingly, tumor-infiltrating $\mathrm{T}$ lymphocytes can reinstate very strong anti-tumor activities, if their environment is switched from the in vivo tumor microenvironment to an in vitro standard normoxic cell culture condition. The significance of in vivo cellular environments on $T$ cell activities was demonstrated in studies showing rapid tolerization of anti-tumor $\mathrm{T}$ cells in intratumoral environments, but not in other tissues [37,38].

Tumors are hypoxic because of abnormal tissue geometry and neovascularization [39]. The demonstration of the critical and non-redundant role of A2AR in inhibition of T cells suggested that hypoxic tumor environments can inhibit anti-tumor $\mathrm{T}$ cells using the same mechanism. The increase of extracellular adenosine levels in tumor microenvironment that was remarkable, and we predicted A2AR-mediated inhibition of incoming anti-tumor T lymphocytes.

Supporting our prediction, it was found that tumor-bearing A2AR-deficient mice endogenously developed anti-tumor $\mathrm{T}$ cells that led to complete tumor rejection, whereas no wild-type mice could reject the tumor [40]. Similar effects were observed in studies of adoptive cancer immunotherapy. Efficacy of anti-tumor $\mathrm{T}$ cell transfer into tumor-bearing mice was significantly improved by co-treatment with A2AR antagonists [40]. Taken together, intratumoral adenosine may be one of the important reasons for rapid inactivation of anti-tumor $\mathrm{T}$ cells in the tumor microenvironment. Inhibition of the adenosine-A2AR pathway is a promising approach to improve cancer immunotherapy to accomplish tumor eradication.

\section{The iatrogenic exacerbation of lung injury by oxygenation}

The oxygenation of patients represents one of the most widely used therapeutic and prophylactic clinical interventions. Clinical oxygenation is intended to alleviate systemic hypoxia; however, there was an alarming possibility that one of the unintended consequences by eliminating hypoxia could be the accompanying elimination of the hypoxia-driven adenosine-A2AR pathway. Of potential therapeutic importance, studies suggest that exposure to high oxygen decreases the levels of extracellular adenosine. By eliminating tissue-protective effect of adenosine-A2AR pathway, the oxygenation may then prevent downregulation of inflammation and thereby exacerbate the pulmonary tissue damage. 
We tested this hypothesis by exposing mice in hyperoxic atmosphere concomitant with the induction of pulmonary inflammation. We found that oxygenation of mice severely exacerbated inflammatory lung damage and even caused death in the majority of mice [15]. Contrary to hyperoxia, exposure to hypoxic atmosphere strongly suppressed lung damage by the A2AR-dependent mechanism. The study shows that acute lung injury due to an overactive inflammatory response would be much more severe if the tissue-protecting effect of hypoxiaadenosinergic pathway was interrupted. Therefore, we reasoned that pathological hypoxia in damaged lungs might not only cause suffering by lowering oxygen supply to vital organs, but also have a lung tissue-protecting function. It is important not to weaken this hypoxia-driven mechanism. Since there are no viable alternatives for the use of oxygen supplementation for respiratory distressed patients, the understanding of the molecular mechanism for hyperoxiainduced exacerbation of pulmonary damage provided a rational basis for effective countermeasures. A possible therapeutic countermeasure could be the administration of A2AR agonist into the lung. This treatment restored protection to inflamed lungs in oxygenated mice by compensating for the loss of endogenous adenosine and reactivating the adenosine-A2AR signaling pathway [15].

\section{Conclusion}

The identification of adenosine-A2AR pathway as an important immunoregulatory mechanism opened a path for the development of new immunomodulatory drugs (Fig. 1). Experimental data suggest that A2AR agonists and antagonists can intervene inflammation by enforcing and blocking A2AR-dependent immunomodulatory mechanism. Newer A2AR agonists having higher selectivity to A2AR have been tested in many different inflammation models. As expected, these new compounds prove effective in the suppression of inflammatory diseases [12,41-43]. Furthermore, A2AR agonists were also found to promote wound healing [44]. Interestingly, A2AR antagonists as well as A2AR-deficiency prevented fibrogenesis through the inhibition of A2AR-mediated collagen biosynthesis $[45,46]$. Since excess fibrosis may cause serious complications, this issue should be considered in the clinical application of A2AR agonist/antagonist. As mentioned above, blockade of adenosine-A2AR pathway also represents a promising approach to promote the efficacy of cancer immunotherapy [40].

Adenosine-A2AR pathway is a unique target for the intervention to a variety of inflammatory conditions. If the inflammatory cells are too active, it may cause exacerbation of allergic and autoimmune diseases. However, if cell activation is poor, it may allow outgrowth of pathogens and tumor cells. A2AR agonist/antagonist may be useful to normalize the imbalance in inflammatory status.

\section{References}

1. Sitkovsky MV, Lukashev D, Apasov S, Kojima H, Koshiba M, Caldwell C, Ohta A, Thiel M. Physiological control of immune response and inflammatory tissue damage by hypoxia-inducible factors and adenosine A2A receptors. Annu Rev Immunol 2004;22:657-682. [PubMed: 15032592]

2. Sitkovsky MV, Ohta A. The 'danger' sensors that STOP the immune response: the A2 adenosine receptors? Trends Immunol 2005;26:299-304. [PubMed: 15922945]

3. Sitkovsky MV, Trenn G, Takayama H. Cyclic AMP-dependent protein kinase as a part of the possible down-regulating pathway in the antigen receptor-regulated cytotoxic T lymphocyte conjugate formation and granule exocytosis. Ann N Y Acad Sci 1988;532:350-358. [PubMed: 2845849]

4. Huang S, Apasov S, Koshiba M, Sitkovsky M. Role of A2a extracellular adenosine receptor-mediated signaling in adenosine-mediated inhibition of T-cell activation and expansion. Blood 1997;90:16001610. [PubMed: 9269779]

5. Vang T, Torgersen KM, Sundvold V, Saxena M, Levy FO, Skalhegg BS, Hansson V, Mustelin T, Tasken K. Activation of the COOH-terminal Src kinase (Csk) by cAMP-dependent protein kinase inhibits signaling through the T cell receptor. J Exp Med 2001;193:497-507. [PubMed: 11181701] 
6. Koshiba M, Rosin DL, Hayashi N, Linden J, Sitkovsky MV. Patterns of A2A extracellular adenosine receptor expression in different functional subsets of human peripheral T cells. Flow cytometry studies with anti-A2A receptor monoclonal antibodies. Mol Pharmacol 1999;55:614-624. [PubMed: 10051547]

7. Fredholm BB, IJzerman AP, Jacobson KA, Klotz KN, Linden J. International Union of Pharmacology. XXV. Nomenclature and classification of adenosine receptors. Pharmacol Rev 2001;53:527-552. [PubMed: 11734617]

8. Cronstein BN, Naime D, Ostad E. The antiinflammatory effects of methotrexate are mediated by adenosine. Adv Exp Med Biol 1994;370:411-416. [PubMed: 7660940]

9. Cronstein BN, Montesinos MC, Weissmann G. Salicylates and sulfasalazine, but not glucocorticoids, inhibit leukocyte accumulation by an adenosine-dependent mechanism that is independent of inhibition of prostaglandin synthesis and p105 of NFkappaB. Proc Natl Acad Sci U S A 1999;96:63776381. [PubMed: 10339595]

10. Ledent C, Vaugeois JM, Schiffmann SN, Pedrazzini T, El Yacoubi M, Vanderhaeghen JJ, Costentin J, Heath JK, Vassart G, Parmentier M. Aggressiveness, hypoalgesia and high blood pressure in mice lacking the adenosine A2a receptor. Nature 1997;388:674-678. [PubMed: 9262401]

11. Chen JF, Huang Z, Ma J, Zhu J, Moratalla R, Standaert D, Moskowitz MA, Fink JS, Schwarzschild MA. A(2A) adenosine receptor deficiency attenuates brain injury induced by transient focal ischemia in mice. J Neurosci 1999;19:9192-9200. [PubMed: 10531422]

12. Ohta A, Sitkovsky M. Role of G-protein-coupled adenosine receptors in downregulation of inflammation and protection from tissue damage. Nature 2001;414:916-920. [PubMed: 11780065]

13. Lukashev D, Ohta A, Apasov S, Chen JF, Sitkovsky M. Cutting edge: Physiologic attenuation of proinflammatory transcription by the Gs protein-coupled A2A adenosine receptor in vivo. J Immunol 2004;173:21-24. [PubMed: 15210754]

14. Day YJ, Marshall MA, Huang L, McDuffie MJ, Okusa MD, Linden J. Protection from ischemic liver injury by activation of A2A adenosine receptors during reperfusion: inhibition of chemokine induction. Am J Physiol Gastrointest Liver Physiol 2004;286:G285-293. [PubMed: 14715520]

- 15. Thiel M, Chouker A, Ohta A, Jackson E, Caldwell C, Smith P, Lukashev D, Bittmann I, Sitkovsky MV. Oxygenation inhibits the physiological tissue-protecting mechanism and thereby exacerbates acute inflammatory lung injury. PLoS Biol 2005;3:e174. [PubMed: 15857155]Oxygenation decreases anti-inflammatory adenosine and subsequently enhances inflammation. This clinically relevant study suggests the mechanism for exacerbated lung injury in oxygenated patients.

16. Németh ZH, Csóka B, Wilmanski J, Xu D, Lu Q, Ledent C, Deitch EA, Pacher P, Spolarics Z, Haskó $\mathrm{G}$. Adenosine A2A receptor inactivation increases survival in polymicrobial sepsis. J Immunol 2006;176:5616-5626. [PubMed: 16622031]

- 17. Zhang N, Yang D, Dong H, Chen Q, Dimitrova DI, Rogers TJ, Sitkovsky M, Oppenheim JJ. Adenosine A2a receptors induce heterologous desensitization of chemokine receptors. Blood 2006;108:38-44. [PubMed: 16522819]Activation of A2AR desensitizes chemokine receptors. This is the first study demonstrating adenosine-mediated regulation of chemotaxis.

18. Sitaraman SV, Merlin D, Wang L, Wong M, Gewirtz AT, Si-Tahar M, Madara JL. Neutrophilepithelial crosstalk at the intestinal lumenal surface mediated by reciprocal secretion of adenosine and IL-6. J Clin Invest 2001;107:861-869. [PubMed: 11285305]

19. Kolachala VL, Vijay-Kumar M, Dalmasso G, Yang D, Linden J, Wang L, Gewirtz A, Ravid K, Merlin D, Sitaraman SV. A2B adenosine receptor gene deletion attenuates murine colitis. Gastroenterology 2008;135:861-870. [PubMed: 18601927]

20. Sun CX, Zhong H, Mohsenin A, Morschl E, Chunn JL, Molina JG, Belardinelli L, Zeng D, Blackburn MR. Role of A2B adenosine receptor signaling in adenosine-dependent pulmonary inflammation and injury. J Clin Invest 2006;116:2173-2182. [PubMed: 16841096]

21. Yang D, Zhang Y, Nguyen HG, Koupenova M, Chauhan AK, Makitalo M, Jones MR, St Hilaire C, Seldin DC, Toselli P, Lamperti E, Schreiber BM, Gavras H, Wagner DD, Ravid K. The A2B adenosine receptor protects against inflammation and excessive vascular adhesion. J Clin Invest 2006;116:1913-1923. [PubMed: 16823489] 
22. Novitskiy SV, Ryzhov S, Zaynagetdinov R, Goldstein AE, Huang Y, Tikhomirov OY, Blackburn MR, Biaggioni I, Carbone DP, Feoktistov I, Dikov MM. Adenosine receptors in regulation of dendritic cell differentiation and function. Blood 2008;112:1822-31. [PubMed: 18559975]

23. Eckle T, Grenz A, Laucher S, Eltzschig HK. A2B adenosine receptor signaling attenuates acute lung injury by enhancing alveolar fluid clearance in mice. J Clin Invest 2008;118:3301-15. [PubMed: 18787641]

24. Morote-Garcia JC, Rosenberger P, Kuhlicke J, Eltzschig HK. HIF-1-dependent repression of adenosine kinase attenuates hypoxia-induced vascular leak. Blood 2008;111:5571-5580. [PubMed: 18309031]

25. Eltzschig HK, Thompson LF, Karhausen J, Cotta RJ, Ibla JC, Robson SC, Colgan SP. Endogenous adenosine produced during hypoxia attenuates neutrophil accumulation: coordination by extracellular nucleotide metabolism. Blood 2004;104:3986-3992. [PubMed: 15319286]

26. Kobie JJ, Shah PR, Yang L, Rebhahn JA, Fowell DJ, Mosmann TR. T regulatory and primed uncommitted CD4 T cells express CD73, which suppresses effector CD4 T cells by converting 5'adenosine monophosphate to adenosine. J Immunol 2006;177:6780-6786. [PubMed: 17082591]

-27. Deaglio S, Dwyer KM, Gao W, Friedman D, Usheva A, Erat A, Chen JF, Enjyoji K, Linden J, Oukka M, Kuchroo VK, Strom TB, Robson SC. Adenosine generation catalyzed by CD39 and CD73 expressed on regulatory T cells mediates immune suppression. J Exp Med 2007;204:1257-1265. [PubMed: 17502665]The authors demonstrate that regulatory T cells express enzymes that degrade ATP to adenosine, and adenosine produced by these enzymes contributes to the suppression of $\mathrm{T}$ cell activation.

28. Choukèr A, Thiel M, Lukashev D, Ward JM, Kaufmann I, Apasov S, Sitkovsky MV, Ohta A. Critical role of hypoxia and A2A adenosine receptors in liver tissue-protecting physiological antiinflammatory pathway. Mol Med 2008;14:116-123. [PubMed: 18163162]

29. Fredholm BB, Bättig K, Holmén J, Nehlig A, Zvartau EE. Actions of caffeine in the brain with special reference to factors that contribute to its widespread use. Pharmacol Rev 1999;51:83-133. [PubMed: 10049999]

30. Foukas LC, Daniele N, Ktori C, Anderson KE, Jensen J, Shepherd PR. Direct effects of caffeine and theophylline on p110 delta and other phosphoinositide 3-kinases. Differential effects on lipid kinase and protein kinase activities. J Biol Chem 2002;277:37124-37130. [PubMed: 12145276]

31. Ohta A, Lukashev D, Jackson EK, Fredholm BB, Sitkovsky M. 1,3,7-trimethylxanthine (caffeine) may exacerbate acute inflammatory liver injury by weakening the physiological immunosuppressive mechanism. J Immunol 2007;179:7431-7438. [PubMed: 18025187]

32. Gattinoni L, Powell DJ Jr, Rosenberg SA, Restifo NP. Adoptive immunotherapy for cancer: building on success. Nat Rev Immunol 2006;6:383-393. [PubMed: 16622476]

-33. Dougan M, Dranoff G. Immune therapy for cancer. Annu Rev Immunol 2009;27:83-117. [PubMed: 19007331]This review provides updated information of current immunotherapy for cancer.

34. Mellor AL, Munn DH. Creating immune privilege: active local suppression that benefits friends, but protects foes. Nat Rev Immunol 2008;8:74-80. [PubMed: 18064049]

35. Gajewski TF, Meng Y, Blank C, Brown I, Kacha A, Kline J, Harlin H. Immune resistance orchestrated by the tumor microenvironment. Immunol Rev 2006;213:131-145. [PubMed: 16972901]

36. Sitkovsky MV, Kjaergaard J, Lukashev D, Ohta A. Hypoxia-adenosinergic immunosuppression: tumor protection by T regulatory cells and cancerous tissue hypoxia. Clin Cancer Res 2008;14:59475952. [PubMed: 18829471]

37. Drake CG, Doody AD, Mihalyo MA, Huang CT, Kelleher E, Ravi S, Hipkiss EL, Flies DB, Kennedy EP, Long M, McGary PW, Coryell L, Nelson WG, Pardoll DM, Adler AJ. Androgen ablation mitigates tolerance to a prostate/prostate cancer-restricted antigen. Cancer Cell 2005;7:239-249. [PubMed: 15766662]

- 38. Bai A, Higham E, Eisen HN, Wittrup KD, Chen J. Rapid tolerization of virus-activated tumorspecific CD8+ T cells in prostate tumors of TRAMP mice. Proc. Natl. Acad. Sci. U. S. A 2008;105:13003-13008. [PubMed: 18723683]Using mice with spontaneous prostate cancer, the authors show that anti-tumor $\mathrm{T}$ cells are inactivated in tumor microenvironment, whereas the same $\mathrm{T}$ cells are strongly active in the distal organ of the same mouse. 
39. Vaupel P, Mayer A. Hypoxia in cancer: significance and impact on clinical outcome. Cancer Metastasis Rev 2007;26:225-239. [PubMed: 17440684]

- 40. Ohta A, Gorelik E, Prasad SJ, Ronchese F, Lukashev D, Wong MK, Huang X, Caldwell S, Liu K, Smith P, Chen JF, Jackson EK, Apasov S, Abrams S, Sitkovsky M. A2A adenosine receptor protects tumors from antitumor T cells. Proc Natl Acad Sci U S A 2006;103:13132-13137. [PubMed: 16916931]A2AR deficiency in T cells promotes tumor elimination. The study suggests the usefulness of A2AR antagonist in the tumor eradication by promoting anti-tumor immune responses.

41. Odashima M, Bamias G, Rivera-Nieves J, Linden J, Nast CC, Moskaluk CA, Marini M, Sugawara K, Kozaiwa K, Otaka M, Watanabe S, Cominelli F. Activation of A2A adenosine receptor attenuates intestinal inflammation in animal models of inflammatory bowel disease. Gastroenterology 2005;129:26-33. [PubMed: 16012931]

42. Lappas CM, Day YJ, Marshall MA, Engelhard VH, Linden J. Adenosine A2A receptor activation reduces hepatic ischemia reperfusion injury by inhibiting CD1d-dependent NKT cell activation. $J$ Exp Med 2006;203:2639-2648. [PubMed: 17088433]

43. Sevigny CP, Li L, Awad AS, Huang L, McDuffie M, Linden J, Lobo PI, Okusa MD. Activation of adenosine $2 \mathrm{~A}$ receptors attenuates allograft rejection and alloantigen recognition. J Immunol 2007;178:4240-4249. [PubMed: 17371980]

44. Montesinos MC, Gadangi P, Longaker M, Sung J, Levine J, Nilsen D, Reibman J, Li M, Jiang CK, Hirschhorn R, Recht PA, Ostad E, Levin RI, Cronstein BN. Wound healing is accelerated by agonists of adenosine A2 (G alpha s-linked) receptors. J Exp Med 1997;186:1615-1620. [PubMed: 9348321]

- 45. Chan ES, Montesinos MC, Fernandez P, Desai A, Delanoc DL, Yee H, Reiss AB, Pillinger MH, Chen JF, Schwarzschild MA, Friedman SL, Cronstein BN. Adenosine A(2A) receptors play a role in the pathogenesis of hepatic cirrhosis. Br J Pharmacol 2006;148:1144-1155. [PubMed: 16783407] Adenosine-A2AR signaling upregulates collagen synthesis and promotes fibrogenesis. The study suggests that when A2AR agonist is used as an anti-inflammatory drug, it may require special attention in order to prevent abnormal tissue remodeling.

46. Fernández P, Trzaska S, Wilder T, Chiriboga L, Blackburn MR, Cronstein BN, Chan ES. Pharmacological blockade of A2A receptors prevents dermal fibrosis in a model of elevated tissue adenosine. Am J Pathol 2008;172:1675-1682. [PubMed: 18467695] 

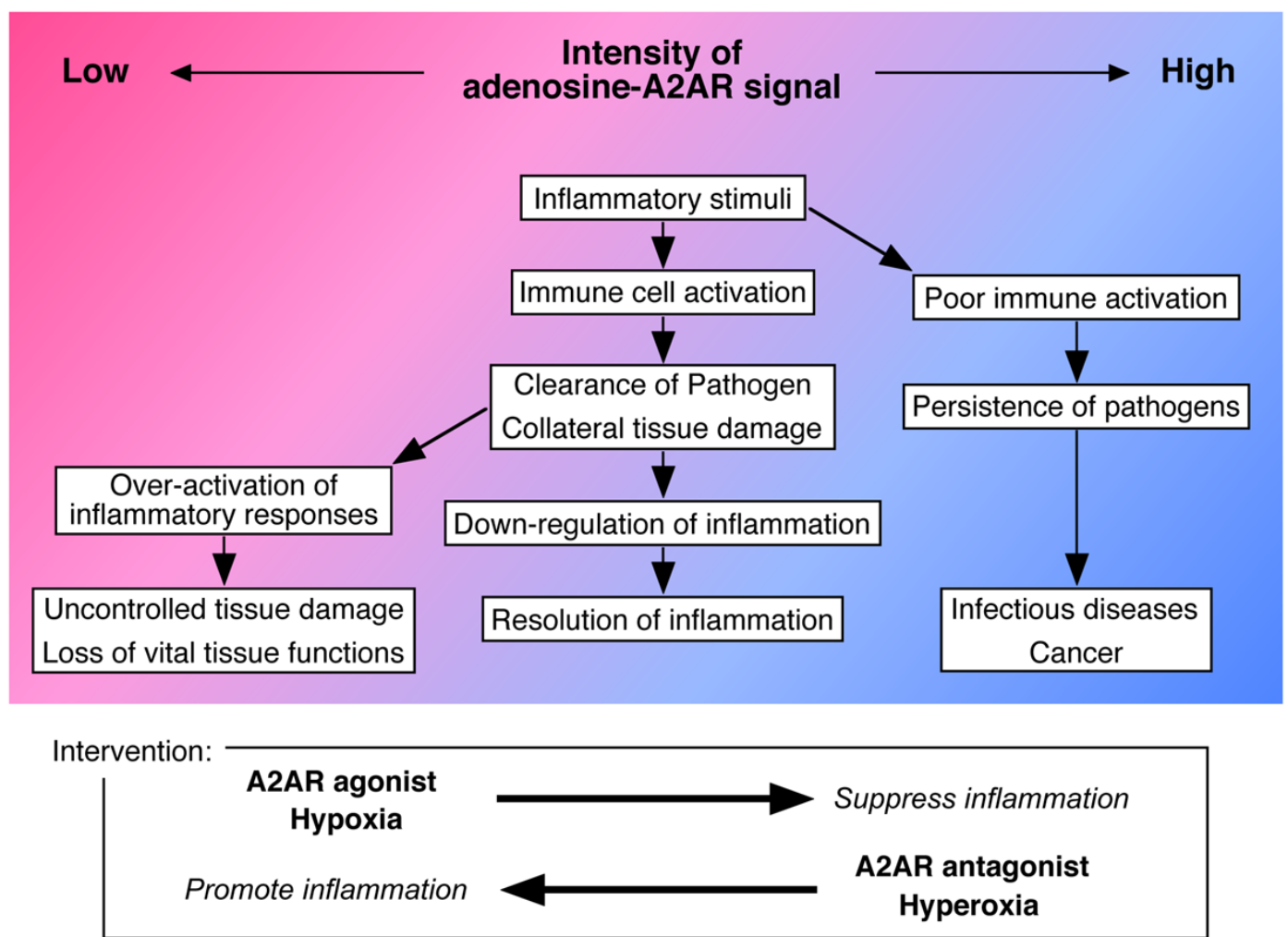

Figure 1.

Adenosine balance regulates the outcome of inflammation. Red and blue background colors represent low and high levels of extracellular adenosine, respectively. In normal situation (middle lane), inflammatory tissue damage following immune activation increases extracellular adenosine levels (red to blue). Adenosine-A2AR signaling controls tissuedamaging activities and inflammation resolves. When immune activation takes place in adenosine-enriched environment (right lane), effector functions of immune cells are insufficient to eliminate pathogens; therefore, it may result in outgrowth of infectious agents and tumor cells. Contrary to this, absence of adenosine-A2AR signaling (left lane) may cause uncontrolled immune activation, which may lead to tissue disfunction. It may be possible to intervene inflammatory responses by modifying the intensity of adenosine-A2AR signal. 